\title{
Wild boar (Sus scrofa) as reservoir of zoonotic yeasts: bioindicator of environmental quality
}

Wafa Rhimi

University of Bari: Universita degli Studi di Bari Aldo Moro

Giovanni Sgroi

University of Bari: Universita degli Studi di Bari Aldo Moro

Chioma Inyang Aneke

University of Bari: Universita degli Studi di Bari Aldo Moro

Giada Annoscia

University of Bari: Universita degli Studi di Bari Aldo Moro

Maria Stefania Latrofa

University of Bari: Universita degli Studi di Bari Aldo Moro

Adriana Mosca

university of bari

Vincenzo Veneziano

University of Naples Federico II: Universita degli Studi di Napoli Federico II

Domenico Otranto

University of Bari: Universita degli Studi di Bari Aldo Moro

Ana Alastruey-Izquierdo

ISCIII: Instituto de Salud Carlos III

Claudia Cafarchia ( $\nabla$ claudia.cafarchia@uniba.it)

Università degli Studi di Bari, Italy https://orcid.org/0000-0002-5632-4472

\section{Research Article}

Keywords: Wild boar, Candida spp., antifungal susceptibility, South Italy

Posted Date: October 19th, 2021

DOI: https://doi.org/10.21203/rs.3.rs-982703/v1

License: (9) (7) This work is licensed under a Creative Commons Attribution 4.0 International License. Read Full License

Version of Record: A version of this preprint was published at Mycopathologia on January 24th, 2022. See the published version at https://doi.org/10.1007/s11046-021-00613-6. 


\begin{abstract}
Wildlife animals are recognized as reservoirs for zoonotic fungi and their faeces might play an important role in introducing pathogens into the environment. Thought wild boar (Sus scrofa) population has dramatically increased across Europe, information about their possible role in dissemination of zoonotic pathogenic yeasts in the environment is scant. Therefore, fecal samples $(n=124)$ from wild boars from Campania region (Southern Italy) were collected and yeasts identified biochemically and molecularly by sequencing of the internal transcribed spacer region (ITS) and their phylogenetical relationship assessed. The antifungal susceptibility profiles of yeasts were also investigated using AFST-EUCAST method. Yeasts were isolated from $50.1 \%$ of the samples with the highest occurrence in samples from the province of Salerno (61.1\%). A total of 368 Candida strains belonging to nine species were identified, with Candida albicans (45.7\%), followed by Candida krusei (15.2\%), Candida slooffiae (9.8\%) and Candida parapsilosis (7.6\%) as the most prevalent identified species. Among $C$. albicans four sequence types (i.e., ST1-ST4) were identified with an intraspecific nucleotide difference up to $0.21 \%$. The ML tree grouped all representative sequence types as paraphyletic clades with those of the references yeast species, respectively and supported by high bootstrap values. Fluconazole was the less active drug whereas, posaconazole, voriconazole, and isavuconazole the most active one. No resistance phenomena were observed for $C$. albicans and high MICs values for 5FC, azoles and echinocandines were registered in non-albicans Candida spp. This study showed, for the first time, the important role of wild boars in dissemination of pathogenic fungi in the environment. The absence of resistance phenomena in the Candida spp. might reflect environmental free from residues of azoles antifungals pollution or chemicals and suggests the role of wild boar as bio indicators of environment quality.
\end{abstract}

\title{
Introduction
}

Fungal infections are considered a public health concern of emerging importance, due to the increased number of human and animal infections [1]. In particular, yeasts of both endogenous (e.g., Candida albicans Candida krusei, Candida parapsilosis,), or exogenous origin (e.g., Candida guilliermondii, Candida fermentati, Candida lusitaniae and Pichia fermentans) may induce cutaneous and systemic diseases in humans and animals [2, 3]. For example, Candida spp., Cryptococcus spp., Trichosporon spp., Rhodotorula spp., Malassezia spp., Sporobolomyces spp. and Saccharomyces spp. are frequently responsible for animal and human infections, especially in immune-compromised individuals [1]. In the last years, an increasing number of non-albicans Candida species (Candida glabrata, Candida parapsilosis, Candida tropicalis, Candida krusei, Candida auris) associated with exogenously acquired infections has been recorded in humans and domestic animals and their low antifungal drug susceptibly has been considered, in some cases, as the major cause of outbreaks [4]. In particular, the role of wild animals in the dissemination of zoonotic pathogens, including fungi, as well as their utility as bio indicators of environmental quality has spurred the interest of the scientific community $[5,6,7]$. Among wild animals, birds have been considered the main global source of pathogenic fungi having an important role in the spreading these organisms thought their faeces $[5,8]$. For example, $C$. albicans has been isolated from gut, cloaca and bird droppings of domestic (i.e., laying hens, broiler chickens, pigeons) and wild birds (rhea, psittacinae, raptors, cockatiels) [8]. Besides Candida, other yeast genera such as Cryptococcus, Geotrichum, Rhodotorula and Trichosporon were also isolated from environments, avian sources, and eggs [5, 9], with a high number of yeasts species showing azole resistance phenomena, mainly from wild and domestic birds $[9,10]$. However, it has been shown that the occurrence of different fungal species and their antifungal susceptibility profiles varied accordingly with animal species and geographical area [8, 11]. Among wild animals, wild boars (Sus scrofa) are considered one of the most extensively distributed mammals of the world, colonizing and occupying a variety of environments, from natural habitats to urban areas, exhibiting high tolerance to human disturbance, while also exploring anthropogenic food available in the environments [12]. The wild boar has dramatically increased in number and distribution, becoming one of the most numerous and hunted ungulate species in Europe [13]. In addition, they are considered model species to unveil the emergence, spread and persistence of antibacterial resistance in the wildlife-livestock interface [14]. Accordingly, wild boar was identified as hosts for filamentous fungi (i.e., Aspergillus fumigatus and Penicillium verrucosum) but their role in spreading pathogenic yeasts has not been well investigated [15]. Therefore, the aims of this study were to i) evaluate the presence of yeasts in the faeces of wild boars and ii) determine the antifungal profile of the isolated strains.

\section{Materials And Methods Study area and sampling}

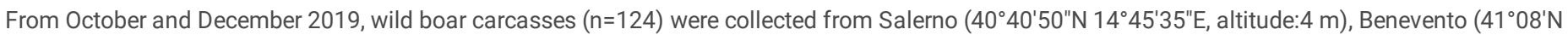
$14^{\circ} 47^{\prime} \mathrm{E}$, altitude: $\left.135 \mathrm{~m}\right)$, Avellino ( $40^{\circ} 54^{\prime} 55^{\prime \prime} \mathrm{N} 14^{\circ} 47^{\prime} 23^{\prime \prime} \mathrm{E}$, altitude: $\left.348 \mathrm{~m}\right)$, and Caserta $\left(41^{\circ} 04^{\prime} \mathrm{N} 14^{\circ} 20^{\prime} \mathrm{E}\right.$, altitude: $\left.68 \mathrm{~m}\right)$ provinces in Campania region, southern Italy $\left(41.488772^{\circ} \mathrm{N}, 15.558892^{\circ} \mathrm{E}\right)$, within a multi-regional health surveillance plan. For each animal, a specific form was filled including animal's age, gender and location of carcass retrieval. All carcasses were analysed within the field activities of the project 'Piano Emergenza Cinghiali in Campania PECC 2016-2019' (protocol number: Decreto Dirigenziale no. 210-Piano B7 DPAR 2018).

\section{Necropsy examination}

Wild boar carcasses were delivered to the Department of Veterinary Medicine and Animal Productions of the University of Naples (Italy), within 24 hours postmortem. In order to perform a complete necropsy examination, all organs and viscera were removed from abdominal and thoracic cavities and carefully inspected to detect any sign/lesion of traceable pathology.

Faecal samples were collected in sterile conditions from wild boar guts, stored at $4^{\circ} \mathrm{C}$ in labelled $50 \mathrm{ml}$ plastic tubes and delivered to the Mycology Unit of Department of Veterinary Medicine, University of Bari (Italy).

\section{Mycological culture and identification procedures}


One gram from each faecal sample was suspended in $9 \mathrm{ml}$ sterile saline solution ( $\mathrm{NaCl} 0.9 \%$ ) containing $1000 \mathrm{mg} / \mathrm{ml}$ streptomycin and $500 \mathrm{UI}$ penicillin/ml. Then, samples were serially diluted in sterile saline solution until reaching a $10^{-4}$ dilution and one hundred microliters of each dilution were cultured onto Sabouraud dextrose agar with chloramphenicol ( $0.5 \mathrm{gr} / \mathrm{l})\left(\mathrm{SAB}\right.$, BioLife $\left.{ }^{\circledR}\right)$, incubated at $32^{\circ} \mathrm{C}$ for 7 days and daily observed. Cultures were defined "positive" when fungal colonies were confirmed microscopically by Gram staining. Colonies were counted, and the yeast population size was expressed as colony forming units (CFU)/gr. Four colonies, for each positive sample were sub-cultured in SAB agar slants for yeast identification at species level. The strains were isolated and identified based on colonial morphology, microscopic and biochemical features as previously reported [11], and by matrix-assisted laser desorption/ ionisation time of flight mass spectrometry (MALDI-TOF MS).

\section{Molecular identification}

All yeast strains were molecularly confirmed by amplification and sequencing of the nuclear ribosomal internal transcribed spacer (ITS) region. In particular, genomic DNA was isolated from each sample using the DNeasy Blood \& Tissue Kit (QIAGEN, Hilden, Germany), following manufacturer's instructions. The nuclear ribosomal ITS region was amplified using ITS1 (5'-TCCGTAGGTGAACCTGCGG-3') and ITS4 (5'-TCCTCCGCTTATTGATATGC-3') primers (REF). The PCR reaction consisted of $4 \mu \mathrm{l}$ genomic DNA $100 \mathrm{ng}$ and $46 \mu \mathrm{l}$ of PCR mix containing $2.5 \mathrm{mM} \mathrm{MgCl}, 10 \mathrm{mM} \mathrm{Tris-HCl}(\mathrm{pH} 8.3)$ and $50 \mathrm{mM} \mathrm{KCl}, 250 \mu \mathrm{M}$ of each dNTP, 100 pmol of each primer and 1.25 U of AmpliTaq Gold (Applied Biosystems, Foster City, CA, USA), and run PCR protocol previously described [9]. PCR products were examined on a $2 \%$ agarose gel stained with GelRed (VWR International PBI, Milano, Italy) and visualised on a Gel Logic 100 gel documentation system (Kodak, New York, USA). The PCR products were purified and sequenced in both directions using the same primers, employing the Big Dye Terminator v.3.1 chemistry in a 3130 Genetic analyzer (Applied Biosystems, California, USA) in an automated sequencer (ABI-PRISM 377). Nucleotide sequences were edited, aligned and analyzed using Bioedit sequence Alignment Editor 7.0.5.3 [16], and compared with available sequences in the GenBank data base by Basic Local Alignment Search Tool (BLAST; http://blast.ncbi.nlm.nih.gov/Blast.cgi).

The percentage of inter and intra-specific ITS nucleotide variation of yeast was calculated by pairwise comparison (Kimura 2-Parameter model) [17] using MEGA5 software [18].

\section{Phylogenetic analysis}

To assess the phylogenetic relationship for each yeast species herein identified, all ITS sequences were analysed along with the reference sequences of Candida spp. isolated from different animal species, from environment and from different geographical areas available in the GenBank database. Phylogenetic tree was inferred using the Maximum Likelihood (ML) method based on the Tamura 3-parameter [19], with Gamma distribution ( $\mathrm{G}$ ) of evolutionary rate differences among sites and on Hasegawa-Kishino-Yano models, respectively, selected by best-fit model [20]. Evolutionary analysis was conducted on 8000 bootstrap replications using the MEGA6 software [21].

\section{Antifungal susceptibility testing}

The antifungal susceptibility profile of Candida spp. strains was evaluated using the reference microdilution method (AFST-EUCAST, definitive document 7.3.2) [22]. The antifungal agents used were itraconazole (ITZ), posaconazole (POS), amphotericin B (AmB), fluconazole (FLZ), isavuconazole (ISA), caspofungin (CP), micafungin (MCF), 5-flucytosine (5FC), anidulafungin (ANI) and voriconazole (VOR) (Sigma-Aldrich, Madrid, Spain). All plates were incubated for $24 \mathrm{hr}$ at $35^{\circ} \mathrm{C}$. Candida parapsilosis ATCC 22019 and Candida krusei ATCC 6258 were used as control strains.

Data obtained were reported as MIC ranges, MIC mean value $(\mathrm{MICm})$, and $\mathrm{MIC}$ at which $50 \%\left(\mathrm{MIC}_{50}\right)$ and $90 \%\left(\mathrm{MIC}_{90}\right)$ of the strains were inhibited.

Isolates were classified as susceptible or resistant according to former and updated EUCAST breakpoints and current EUCAST ECOFFs [23]. The following MIC values for ISA ( $\mathrm{MIC}>0.5 \mu \mathrm{g} / \mathrm{mL})$, for $\mathrm{CP}(\mathrm{MIC}>1 \mu \mathrm{g} / \mathrm{mL})$ and for $5 \mathrm{FC}(\mathrm{MIC}>0.5 \mu \mathrm{g} / \mathrm{mL})$ were considered to indicate probable resistance [24-26].

Candida spp. with no available breakpoints and EUCAST ECOFFs were classified as strains with high MICs values (low susceptible) when their MIC values were equal or higher that those registered for resistant $C$. albicans strains.

\section{Statistical analysis}

The distribution of positive/negative animals in the study areas was obtained with ArcGIS (version 10.3, ESRI, Redlands, CA, USA) and associated with the administrative boundaries of provinces, regional and national parks.

A Chi-squared test was used to assess statistical differences among wild boar's age, gender and location. A P value of $<0.05$ was considered significant.

\section{Results}

\section{Necropsy examination and culture yeast identification}

At necropsy, all animals showed the absence of clinical signs of localized or systemic infections. Yeasts were isolated from $50.1 \%$ of the wild boar faecal samples with the highest occurrence in Salerno (61.1\%) and the lowest in Avellino (34.5\%) provinces (Table 1, Fig. 1). A greater population size of yeasts (1856.9 \pm 5073.3$)$ was recorded and the higest values from samples collected in Caserta (3750.8 \pm 9292.7$)$ and in Salerno (1380.8 \pm 3334.7$)$. A total of eleven yeasts species belonging to Candida, Geotrichum and Rodotorula genera were isolated with the highest species diversity in samples collected from Salerno. No significant differences in yeasts occurrence were found according to gender or sex of tested animals (Table 1) but the highest diversity of yeast species was recorded in adult animals (Table 1 ). 
Table 1

Number and percentage of faeces from wild boar positive for yeasts divided according to sex, age, and origin. Population size expressed as colony forming unit/gr (CFU/gr) and number of isolated yeasts species were also reported. The statistically significant differences were reported with the same superscript letters

\begin{tabular}{|c|c|c|c|c|}
\hline \multicolumn{2}{|c|}{ Wild boars } & \multirow{2}{*}{$\begin{array}{l}\text { Pos/Total (\%) } \\
36 / 68(52.9)\end{array}$} & \multirow{2}{*}{$\begin{array}{l}\text { Means CFU } \pm \text { sd } \\
1799.9 \pm 4310.7\end{array}$} & \multirow{2}{*}{$\begin{array}{l}\text { Number of Yeast spp } \\
\text { isolated } \\
11 / 11(100)\end{array}$} \\
\hline Sex & Male & & & \\
\hline & Female & $27 / 56(48.2)$ & $1941.1 \pm 6030.8$ & 9/11 (81.8) \\
\hline \multirow[t]{2}{*}{ Age } & Young & 14/24(58.3) & $827.9 \pm 1166.8^{b}$ & 6/11 (72.7) \\
\hline & Adults & 49/100(49) & $2195.5 \pm 5753.2^{b}$ & $11 / 11(100)$ \\
\hline \multirow[t]{4}{*}{ Origin } & Salerno & $33 / 54(61.1)^{a}$ & $1380.8 \pm 3334.7$ & $10 / 11(90.9)^{c}$ \\
\hline & Benevento & $8 / 21(38.1)$ & $401.9 \pm 505.9$ & $7 / 11(63.6)$ \\
\hline & Avellino & $10 / 29(34.5)^{a}$ & $873.5 \pm 1062$ & 7/11(63.6) \\
\hline & Caserta & $12 / 20(60)$ & $3750.8 \pm 9292.7$ & $5 / 11(45.4)^{c}$ \\
\hline Total & & $63 / 124(50.1)$ & $1856.9 \pm 5073.3$ & $11 / 11(100)$ \\
\hline
\end{tabular}

\section{Molecular identification and phylogenetic analysis}

Only Candida species were employed for identification purposes. A total of 368 Candida spp. strains were isolated and molecularly identified as belonging to nine species (Table 2). Candida albicans was the most frequently isolated species (45.7\%), followed by Candida krusei (15.2\%), while $C$. lusitaniae was the less frequent one (1.1\%) (Table 2). Sequences of amplicons representing the strains of Candida spp. showed the nucleotide identity of $100 \%$ with reference strains from GenBank (Table 2, Fig. 2). Only one sequence type was identified for non-Candida albicans spp. (Table 2, Fig. 2), while four sequence types, named from ST1 to ST4 were identified for $C$. albicans with an overall mean intraspecific variation ranging from $0.21 \neg 0.64 \%$. The ITS interspecific nucleotide variation among Candida species ranged from 0.70-65.6\% (Table 3). The phylogenetic analyses confirm the molecular identification in clustering each yeast species within the clade of the same species as a paraphyletic group, being supported by good bootstrap values (i.e., up to $99 \%$ ) (Fig. 2). In particular, each Candida spp. or ST clustered in the clade including Candida strains from different geographic areas and causing human and animal infections (Fig. 2). All representative sequence types were deposited in the NCBI Sequence Read Archive under accession numbers MW279244- MW279253.

Table 2

Candida species from wild boars: Frequencies, internal transcribed spacer (ITS) sequence types (ST) and percentage of sequence nucleotide identity with GenBank accession number

\begin{tabular}{|c|c|c|c|c|}
\hline Candida spp. & $\begin{array}{l}\text { Pos/Tot } \\
\text { (\%) }\end{array}$ & Sequence types (\%) & Nucleotide identity & GenBank accession number \\
\hline \multirow[t]{4}{*}{ Candida albicans } & $168 / 368(45.7)$ & ST1 (7.1) & $100 \%$ & LT577608 \\
\hline & & ST2 (14.3) & $100 \%$ & LT577608 \\
\hline & & ST3 (7.1) & $100 \%$ & MN398198 \\
\hline & & ST4 (71.5) & $100 \%$ & MT131348 \\
\hline Candida krusei & $56 / 368(15.2)$ & ST1 (100) & $100 \%$ & KX218263 \\
\hline Candida slooffiae & $36 / 368$ (9.8) & ST1 (100) & $100 \%$ & KY103671 \\
\hline Candida parapsilosis & 28/368 (7.6) & ST1 (100) & $100 \%$ & KY075672 \\
\hline Candida fermentati & 24/368 (6.5) & ST1 (100) & $100 \%$ & NR 149348 \\
\hline Candida guilliermondii & $20 / 368(5.4)$ & ST1 (100) & $100 \%$ & KF746422 \\
\hline $\begin{array}{l}\text { Candida lambica } \\
\text { (Pichia fermentans) }\end{array}$ & $20 / 368(5.4)$ & ST1 (100) & $100 \%$ & MT64542 \\
\hline Candida metapsilosis & 12/368 (3.3) & ST1 (100) & $100 \%$ & MF940132 \\
\hline Candida Iusitaniae & $4 / 368(1.1)$ & ST1 (100) & $100 \%$ & MT534186 \\
\hline
\end{tabular}


Table 3

Pairwise comparisons (PwC) of sequence differences (\%) in ITS among all Candida spp strains cultured from wild boar faeces

\begin{tabular}{|c|c|c|c|c|c|c|c|c|}
\hline Candida spp & C. albicans & C. metapsilosis & C. parapsilosis & C. guilliermondii & C. fermentati & C. slooffiae & C. Iusitaniae & $\begin{array}{l}\text { C. } \\
\text { lambica }\end{array}$ \\
\hline \multicolumn{9}{|l|}{ C. albicans } \\
\hline C. metapsilosis & $17.55 \%$ & & & & & & & \\
\hline C. parapsilosis & $18.68 \%$ & $1.41 \%$ & & & & & & \\
\hline C. slooffiae & $40.86 \%$ & $49.31 \%$ & $49.70 \%$ & $40.98 \%$ & $40.75 \%$ & & & \\
\hline C. lusitaniae & $60.51 \%$ & $65.62 \%$ & $63.04 \%$ & $60.82 \%$ & $59.62 \%$ & $65.15 \%$ & & \\
\hline C. lambica & $54.76 \%$ & $55.77 \%$ & $57.01 \%$ & $53.84 \%$ & $53.39 \%$ & $58.55 \%$ & $48.97 \%$ & \\
\hline
\end{tabular}

\section{Antifungal susceptibility testing}

The MICs for the quality control strain Candida parapsilosis ATCC 22019 and Candida krusei ATCC 6258 were all within the reference ranges.

FLZ was the less active drug whereas, POS, VOR and ISA were the most active azoles, regardless the species The antifungal profile varied accordingly to Candida species (Table 4). 
Table 4

Minimum inhibitory concentration (MIC, $\mu \mathrm{g} / \mathrm{mL}$ ) data of Itraconazole (ITZ), Posaconazole (POS), Amphotericin (AmB), Voriconazole (VOR), Fluconazole (FLZ), Isavuconazole (ISA), Caspofungin (CP), Micafungin (MCF), Flucytosine (5FC), anidulafungin (ANI), of Candida spp. from wild boars.

\begin{tabular}{|c|c|c|c|c|c|c|c|c|c|c|c|}
\hline Candida spp. & MIC data & ITZ & POS & AMB & VOR & FLZ & ISA & $\mathrm{CP}$ & MICA & $5 F C$ & ANI \\
\hline \multirow{5}{*}{$\begin{array}{l}\text { Candida albicans } \\
(n=168)\end{array}$} & RANGE & $0.015-0.06$ & $0.03-0.06$ & $0.03-0.5$ & $0.015-0.25$ & $0.12-4$ & $0.015-0.25$ & $0.25-0.5$ & $0.004-0.06$ & $0.12-4$ & $0.007-0.03$ \\
\hline & MIC50 & 0.015 & 0.03 & 0.25 & 0.015 & 0.12 & 0.015 & 0.25 & 0.008 & 0.25 & 0.007 \\
\hline & MIC90 & 0.03 & 0.06 & 0.5 & 0.12 & 0.25 & 0.12 & 0.5 & 0.008 & 0.5 & 0.03 \\
\hline & MICm(dev.st) & $0.03(0.04)$ & $0.04(0.02)$ & $0.25(0.1)$ & $0.04(0.05)$ & $0.32(0.83)$ & $0.06(0.09)$ & $0.38(0.3)$ & $0.01(0.02)$ & 0.34 & $0.02(0.03)$ \\
\hline & & & & & & & & & & $(0.59)$ & \\
\hline \multirow{4}{*}{$\begin{array}{l}\text { Candida krusei ( } \mathrm{n} \\
=56 \text { ) }\end{array}$} & RANGE & $0.06-0.5$ & $0.06-0.5$ & $0.03-1$ & $0.12-0.5$ & $16-64$ & $0.12-0.25$ & $0.25-1$ & $0.015-0.25$ & $1-4$ & $0.007-0.06$ \\
\hline & MIC50 & 0.25 & 0.12 & 0.5 & 0.25 & 32 & 0.12 & 1 & 0.125 & 2 & 0.007 \\
\hline & MIC90 & 0.5 & 0.25 & 1 & 0.25 & 32 & 0.25 & 1 & 0.25 & 4 & 0.06 \\
\hline & $\begin{array}{l}\mathrm{MICm} \\
\text { (dev.st) }\end{array}$ & $0.25(0.16)$ & $0.23(0.13)$ & $0.64(0.35)$ & $0.24(0.13)$ & $30.9(11.68)$ & $0.14(0.06)$ & $0.86(0.29)$ & $0.17(0.08)$ & $2.6(1.08)$ & $0.04(0.02)$ \\
\hline \multirow{5}{*}{$\begin{array}{l}\text { Candida slooffiae } \\
(\mathbf{n}=\mathbf{3 6})\end{array}$} & RANGE & $0.015-0.25$ & $0.015-0.25$ & $0.25-1$ & $0.015-0.25$ & $0.25-32$ & $0.015-0.25$ & $0.25-1$ & $0.008-0.25$ & $0.12-2$ & $0.007-0.06$ \\
\hline & MIC50 & 0.015 & 0.015 & 0.25 & 0.015 & 0.25 & 0.015 & 0.5 & 0.015 & 0.5 & 0.007 \\
\hline & MIC90 & 0.25 & 0.25 & 0.5 & 0.25 & 32 & 0.12 & 1 & 0.25 & 2 & 0.06 \\
\hline & $\mathrm{MICm}$ & $0.10(0.11)$ & $0.10(0.10)$ & 0.39 & $0.13(0.11)$ & $10.88(13.66)$ & $0.08(0.08)$ & $0.5(0.31)$ & $0.089(0.1)$ & $1.0(0.96)$ & $0.02(0.023)$ \\
\hline & (dev.st) & & & $(0.27)$ & & & & & & & \\
\hline \multirow{4}{*}{$\begin{array}{l}\text { Candida } \\
\text { parapsilosis ( } \mathbf{n} \\
=\mathbf{2 8} \text { ) }\end{array}$} & RANGE & $0.06-0.12$ & $0.015-0.06$ & $0.25-1$ & $0.015-0.25$ & $0.12-4$ & $0.015-0.12$ & $0.5-2$ & $0.5-1$ & $0.12-0.25$ & $1-2$ \\
\hline & MIC50 & 0.12 & 0.06 & 0.5 & 0.12 & 1 & 0.12 & 2 & 0.5 & 0.12 & 1 \\
\hline & MIC90 & 0.12 & 0.06 & 1 & 0.25 & 4 & 0.12 & 2 & 1 & 0.25 & 2 \\
\hline & $\begin{array}{l}\mathrm{MICm} \\
\text { (dev.st) }\end{array}$ & $0.10(0.09)$ & $0.05(0.02)$ & $0.68(0.3)$ & $0.13(0.09)$ & $1.62(1.76)$ & $0.082(0.05)$ & $1.5(0.65)$ & $0.57(0.19)$ & $\begin{array}{l}0.16 \\
(0.06)\end{array}$ & $1.28(0.48)$ \\
\hline \multirow{4}{*}{$\begin{array}{l}\text { Candida } \\
\text { fermentati }(\mathbf{n}=\mathbf{2 4})\end{array}$} & RANGE & $0.06-0.5$ & $0.06-1$ & $0.06-0.5$ & $0.015-0.12$ & $1-16$ & $0.06-0.25$ & $0.5-1$ & $0.03-0.5$ & $0.12-2$ & $0.03-2$ \\
\hline & MIC50 & 0.12 & 0.12 & 0.25 & 0.06 & 2 & 0.12 & 0.5 & 0.125 & 0.12 & 0.125 \\
\hline & MIC90 & 0.25 & 0.25 & 0.5 & 0.12 & 8 & 0.12 & 1 & 0.50 & 0.12 & 2 \\
\hline & $\begin{array}{l}\mathrm{MICm} \\
\text { (dev.st) }\end{array}$ & $0.22(0.2)$ & $0.3(0.35)$ & $0.34(0.19)$ & $0.07(0.04)$ & $5.5(5.7)$ & $0.13(0.06)$ & $0.75(0.3)$ & $0.3(0.22)$ & $0.43(0.77)$ & $0.87(0.95)$ \\
\hline \multirow{4}{*}{$\begin{array}{l}\text { Candida lambica } \\
(n=20)\end{array}$} & RANGE & $0.06-0.12$ & $0.03-0.12$ & $0.03-0.06$ & $0.03-0.06$ & 8 & $0.015-0.03$ & $0.25-0.5$ & $0.015-0.03$ & 0.25 & $0.007-0.015$ \\
\hline & MIC50 & 0.012 & 0.12 & 0.03 & 0.03 & 8 & 0.03 & 0.5 & 0.015 & 0.25 & 0.007 \\
\hline & MIC90 & 0.12 & 0.12 & 0.06 & 0.06 & 8 & 0.03 & 0.5 & 0.03 & 0.25 & 0.015 \\
\hline & $\begin{array}{l}\mathrm{MICm} \\
\text { (dev.st) }\end{array}$ & $0.1(0.03)$ & $0.08(0.05)$ & $0.04(0.01)$ & $0.05(0.02)$ & $8(0)$ & $0.02(0.01)$ & $0.4(0.14)$ & $0.02(0.01)$ & $0.25(0)$ & $0.01(0.004)$ \\
\hline \multirow{4}{*}{$\begin{array}{l}\text { Candida } \\
\text { guilliermondii ( } \mathbf{n} \\
=20 \text { ) }\end{array}$} & RANGE & $0.12-0.25$ & $0.06-0.25$ & $0.25-1$ & $0.06-0.5$ & $4-32$ & $0.12-0.25$ & $0.5-1$ & $0.008-0.25$ & $0.12-1$ & $0.03-1$ \\
\hline & MIC50 & 0.25 & 0.12 & 0.25 & 0.25 & 16 & 0.12 & 1 & 0.125 & 0.12 & 0.03 \\
\hline & MIC90 & 0.25 & 0.12 & 0.5 & 0.5 & 32 & 0.25 & 1 & 0.125 & 0.25 & 0.03 \\
\hline & $\begin{array}{l}\text { MICm } \\
\text { (dev.st) }\end{array}$ & $0.22(0.06)$ & $0.14(0.1)$ & $0.45(0.32)$ & $0.32(0.17)$ & $26.4(23.3)$ & $0.2(0.07)$ & $0.8(0.3)$ & $0.11(0.1)$ & $0.35(0.37)$ & $0.22(0.44)$ \\
\hline \multirow{3}{*}{$\begin{array}{l}\text { Candida } \\
\text { metapsilosis ( } \mathrm{n} \\
=12 \text { ) }\end{array}$} & RANGE & $0.12-0.25$ & $0.06-0.25$ & 0.25 & $0.015-0.03$ & $0.25-0.5$ & 0.015 & $0.5-1$ & $0.004-0.25$ & 0.12 & $0.125-0.5$ \\
\hline & MIC50 & 0.12 & 0.25 & 0.25 & 0.015 & 0.25 & 0.015 & 0.5 & 0.25 & 0.12 & 0.125 \\
\hline & MIC90 & 0.25 & 0.25 & 0.25 & 0.03 & 0.5 & 0.015 & 1 & 0.25 & 0.12 & 0.5 \\
\hline
\end{tabular}




\begin{tabular}{|c|c|c|c|c|c|c|c|c|c|c|c|}
\hline Candida spp. & MIC data & ITZ & POS & AMB & VOR & FLZ & ISA & $\mathrm{CP}$ & MICA & $5 \mathrm{FC}$ & ANI \\
\hline & $\begin{array}{l}\text { MICm } \\
\text { (dev.st) }\end{array}$ & $0.2(0.08)$ & $0.19(0.11)$ & $0.25(0)$ & $0.02(0.01)$ & $0.33(0.087)$ & $0.015(0)$ & $0.7(0.3)$ & $0.17(0.14)$ & $0.12(0)$ & $0.25(0.21)$ \\
\hline \multirow{4}{*}{$\begin{array}{l}\text { Candida lusitaniae } \\
(n=4)\end{array}$} & RANGE & 0.25 & 0.06 & 0.03 & 0.12 & 4 & 0.015 & 0.5 & 0.015 & 2 & 0.004 \\
\hline & MIC50 & 0.25 & 0.06 & 0.03 & 0.12 & 4 & 0.015 & 0.5 & 0.015 & 2 & 0.004 \\
\hline & MIC90 & 0.25 & 0.06 & 0.03 & 0.12 & 4 & 0.015 & 0.5 & 0.015 & 2 & 0.004 \\
\hline & $\begin{array}{l}\text { MICm } \\
\text { (dev.st) }\end{array}$ & $0.25(0)$ & $0.06(0)$ & $0.25(0)$ & $0.12(0)$ & $4(0)$ & $0.015(0)$ & $0.50)$ & $0.015(0)$ & $2(0)$ & $0.004(0)$ \\
\hline
\end{tabular}

ITZ, MICA and ANI were the most active drugs and CP the less active one $(0.38 \mu \mathrm{g} / \mathrm{ml})$ for $C$ albicans. For $C$. krusei, the highest sensitivity was recorded for ANI $\left(\mathrm{MIC}_{\mathrm{m}}=0.04 \mu \mathrm{g} / \mathrm{ml}\right)$ and lowest for FLZ $\left(\mathrm{MIC}_{\mathrm{m}} 30.09 \mu \mathrm{g} / \mathrm{ml}\right)$. For C. parapsilosis, the lowest $\mathrm{MIC}_{\mathrm{m}}$ value was recorded for VOR, POS, ISA and the highest MIC $\mathrm{m}$ were registered for $\mathrm{CP}$ and $\mathrm{ANI}$. C. slooffiae, C. fermentati, C. lambica, C. guilliermondii and C. lusitaniae showed low susceptibility to FLZ (Table 4).

Based on the clinical breakpoints and current EUCAST ECOFFs no resistance phenomena were observed for $C$. albicans. High MICs values (Table 5) were detected for 5FC in C. krusei and C. Iusitaniae, for CP in C. parapsilosis, for ITZ, POS and FLZ in C. slooffiae, and C. lambica (from $33.3 \%$ to $100 \%$ ), for ITZ and POS in C. metapsilosis. for MICA and AND in C. slooffiae, C. fermentati and C. guilliermondii (from 20 to $100 \%$ ).

Table 5

Number and percentage of Candida spp. from wild boar resistant or low susceptible (MIC values higher that those registered for resistant $C$. albicans) to itrac posaconazole (POS), amphotericin (AmB), voriconazole (VOR), fluconazole (FLZ), isavuconazole (ISA), caspofungin (CP), micafungin (MCF), 5-Flucytos

\begin{tabular}{|c|c|c|c|c|c|c|c|c|c|}
\hline & ITZ & POS & AMB & VOR & FLZ & ISA & $\mathrm{CP}$ & MICA & $5 \mathrm{FC}$ \\
\hline $\begin{array}{l}\text { C. albicans (n } \\
=168)\end{array}$ & $0 / 168(0 \%)$ & $0 / 168(0 \%)$ & $0 / 168(0 \%)$ & $0 / 168(0 \%)$ & $0 / 168(0 \%)$ & $0 / 168(0 \%)$ & $0 / 168(0 \%)$ & $0 / 168(0 \%)$ & $0 / 168(0 \%)$ \\
\hline $\begin{array}{l}\text { C. krusei ( } \mathrm{n} \\
=56 \text { ) }\end{array}$ & $0 / 56(0 \%)$ & $0 / 56(0 \%)$ & $0 / 56(0 \%)$ & $0 / 56(0 \%)$ & $0 / 56(0 \%)$ & $0 / 56(0 \%)$ & $0 / 56(0 \%)$ & $0 / 56(0 \%)$ & $56 / 56(100 \%)$ \\
\hline $\begin{array}{l}\text { C. slooffiae } \\
(n=36)\end{array}$ & $\begin{array}{l}12 / 36 \\
(33.3 \%)\end{array}$ & $20 / 36(55.6 \%)$ & $0 / 36(0 \%)$ & $0 / 36(0 \%)$ & $16 / 36(44 \%)$ & $0 / 36(0 \%)$ & $0 / 36(0 \%)$ & $16 / 36(44 \%)$ & $16 / 36(44 \%)$ \\
\hline $\begin{array}{l}\text { C. } \\
\text { parapsilosis } \\
(n=28)\end{array}$ & $0 / 28(0 \%)$ & $0 / 28(0 \%)$ & $0 / 28(0 \%)$ & $0 / 28(0 \%)$ & $0 / 28(0 \%)$ & $0 / 28(0 \%)$ & 16/28(57.1\%) & $0 / 28(0 \%)$ & $0 / 28(0 \%)$ \\
\hline $\begin{array}{l}\text { C. fermentati } \\
(n=24)\end{array}$ & $0 / 24(0 \%)$ & $4 / 24(16.6 \%)$ & $0 / 24(0 \%)$ & $0 / 24(0 \%)$ & $0 / 24(0 \%)$ & $0 / 24(0 \%)$ & $0 / 24(0 \%)$ & $24 / 24(100 \%)$ & $4 / 24(16.6 \%)$ \\
\hline $\begin{array}{l}\text { C. } \\
\text { guilliermondii } \\
(n=20)\end{array}$ & $0 / 20(0 \%)$ & $0 / 20(0 \%)$ & $4 / 20(20 \%)$ & $8 / 20(40 \%)$ & $8 / 20(40 \%)$ & $0 / 20(0 \%)$ & $0 / 20(0 \%)$ & $16 / 20(80 \%)$ & $4 / 20(20 \%)$ \\
\hline $\begin{array}{l}\text { C. } \\
\text { metapsilosis } \\
(n=12)\end{array}$ & $8 / 12(66.6 \%)$ & $8 / 12(66.6 \%)$ & $0 / 12(0 \%)$ & $0 / 12(0 \%)$ & $0 / 12(0 \%)$ & $0 / 12(0 \%)$ & $0 / 12(0 \%)$ & $0 / 12(0 \%)$ & $0 / 12(0 \%)$ \\
\hline $\begin{array}{l}\text { C. lambica ( } n \\
=20 \text { ) }\end{array}$ & $12 / 20(60 \%)$ & $12 / 20(60 \%)$ & $0 / 20(0 \%)$ & $0 / 20(0 \%)$ & $20 / 20(100 \%)$ & $0 / 20(0 \%)$ & $0 / 20(0 \%)$ & $0 / 20(0 \%)$ & $0 / 20(0 \%)$ \\
\hline $\begin{array}{l}\text { C. lusitaniae } \\
(\mathrm{n}=4)\end{array}$ & $0 / 4(0 \%)$ & $0 / 4(0 \%)$ & $0 / 4(0 \%)$ & $0 / 4(0 \%)$ & $0 / 4(0 \%)$ & $0 / 4(0 \%)$ & $0 / 4(0 \%)$ & $0 / 4(0 \%)$ & $4 / 4(100 \%)$ \\
\hline
\end{tabular}

\section{Discussion}

Data indicated that wild boar harbour, in their faeces many pathogenetic yeasts thus, suggesting their potential role in the spreading these organisms in the environment. The high density of yeasts in the faeces (i.e., CFU $\geq 10^{3}$ ) of a large population of wild boar (i.e., $50 \%$ ) might indicate that the yeasts have also a role in causing infection in these animals. However, the absence of any signs of localized or systemic infections at the necropsy, confirm that these animals play a role in spreading pathogenic microorganisms in the environment. A similar picture was observed in others wild and domestic animals (i.e., rodents, cats), that are often asymptomatic carriers of pathogenic yeasts to humans [27]. In addition, the large range of wild boar movements (i.e., up to 16 Km) [28], as well as the changes of human habitation to suburban areas, the increased deforestation may increase the dissemination of fungal organisms of zoonotic concern $[6,29]$. Similar prevalence of yeasts occurrence was previously observed in swine $(44.2 \%)$, in cattle $(46.8 \%)$, and in horses $(56 \%)$ but it is lower than in wild birds (90\%), thus confirming that host environment, as well as lifestyle-related factors of a host might play a primary role in shaping the fungal community [30]. In addition, the age of animals could be a factor affecting the diversity in the yeast species being lower in young animals compared to adults in which fungal flora showed the highest variety of yeast species. These finding might be due to the microbial community of adult animal is gradually formed based on exposure factors to different ecological and environmental conditions and immune system response [31]. 
In this study, Candida spp. was the most frequent isolated yeast genus with a mean population size $\geq 10^{4} \mathrm{CFU} / \mathrm{gram}$ of faeces. The occurrence of these fungi in the faeces of examined animals could be explained by the fact that most of these yeast species are commensal organisms of intestinal and cloacal tracts of animals, whereas the high population density could be the result of compromised status of hosts or environmental contamination and consumption of contaminated food. On the other hand, these findings also indicate that wild boars harbour many important infectious agents that could be transmissible to domestic pigs and other animal species, including humans [6,32]. Overall, all the isolated Candida species are causative agents of candidiasis or candidemia with clinical manifestations in humans (e.g., fungaemia, endophthalmitis, arthritis and endocarditis) which may ultimately cause high mortality and lifethreatening infections in immune-compromised patients [33]. C. albicans is the most common agent of life-threatening human candidemia and candidiasis [34] and it has also been recovered from both wild and domestic animals, such as birds and reptiles [35]. Candida krusei and C. parapsilosis were retrieved in wild birds, cockatiels, dogs, cows and pigs faecal samples [10] and were considered the most common non-albicans Candida species causing severe infection in immune-compromised human patients [36]. In addition, C. krusei strains were characterized by a high mortality rate (40-58\%) and poor response to standard antifungal therapies [37].

C. slooffiae was never reported as causative agent of severe infection in animals and humans but it has been frequently found in different parts of the gastrointestinal tract of apparently healthy pigs and therefore considered as a natural inhabitant of the porcine intestinal environment [38]. As far as $C$. guilliermondii and $C$. Iusitaniae, they are rare human fungal pathogens, causing fungemia not exceeding $5 \%$ of nosocomial systemic infections worldwide. However, in certain geographical areas such as Brazil, India and Italy, over $10 \%$ of all the candidemia cases were caused by these species [39, 40$]$. All isolates molecularly identified to species level in this study showed very low intraspecific and high interspecific variability. An increasing number of studies reported that ITS-based identification system was accurate and applicable, even to strains with atypical morphological features [41]. Here, C. guilliermondii, C. fermentati, as well as $C$. parapsilosis and $C$. metapsilosis, were molecularly differentiated, confirming the utility of ITS sequence polymorphism analysis. Sequence analysis of the data revealed the circulation of four different STs for $C$. albicans, and one ST for others Candida spp. (C. parapsilosis, $C$. krusei, $C$. guilliermondii, C. fermentati, C. slooffiae, Clusitaniae, P.fermentans). These findings confirmed previous results suggesting that the genetic variability observed in ITS region, was more likely to be found in Candida species primarily involved as commensal organisms while species predominantly associated with an exogenously origin, such as, C. guilliermondii, C. fermentati, C. slooffiae, C. Iusitaniae and C. lambica showed low intraspecific variability [2, 3]. The ML tree clearly indicates that all strains of each Candida species from wild boars were phylogenetically close to the same species recovered from immunecompromised patients suffering for a variety of lesions (e.g., oropharyngeal candidiasis, onychomycosis, persistent candidemia, candiduria, atopic dermatitis and vulvovaginal candidiasis). The phylogenetic analysis also showed that strains of $C$. albicans, C. parapsilosis, C. metapsilosis, and C. guilliermondii from wild boar clustered with those from domestic animals (i.e., sheep, cat and dog), from insect (i.e., Anopheles darling) and from environmental sources (i.e., tree, herb, egg, orange, water, soil) from Italy, as well as from other geographical locations (i.e., France, Poland, Hungary, Brazil, Argentina, Iran) [42]. However, MLST analysis should be done in the feature in order to confirm the molecular epidemiology of the fungal diseases caused by this yeast species. Overall, all these findings might suggest a clonal origin of these strains and their ability to circulate amongst different hosts and environment thus reinforcing the hypothesis that pathogens may be transmitted from wild boar (e.g., emerging zoonoses) to environment and to humans. Nowadays, wild boar populations are widespread, with considerably large home ranges, overlapping their habitat with livestock and humans and serving as an interface between human-influenced settings and natural areas [43].

As far the antifungal susceptibility profile of these yeasts the finding of high susceptibility for POS, VOR and ISA for all Candida spp. confirms the results of previous studies and suggests the usefulness of these drugs for treating tested these infections [44, 45]. However, a low susceptibility for azoles and echinocandins were detected among non-albicans Candida spp. strains. The high MICs for fluconazole in $C$. krusei and $C$. guilliermondii are a constant finding and may reflect an intrinsic resistance or acquisition of resistance followed to drugs exposure [46]. On the contrary, the high FLZ MIC values registered for $C$. lambica and $C$. sloffiae are of interest. In particular, these yeasts species are mainly isolated from environment or as commensal organism of porcine gut [47]. Usually, a very low MIC values for FLZ were registered in yeasts collected from their natural habitat whereas high FLZ MIC values were reported in isolates from human infections thus suggesting an acquired resistance phenomena during therapy. Consequently, the isolation of low FLZ susceptible yeast in faeces from wild board might be due the acquisition of these yeasts from anthropized environments or for the acquisition of azole resistance from environment azole exposition. However due to the small number of studies on antifungal susceptibility of these yeast species no any straightforward conclusions can be herein allowed. Accordingly, the poor susceptibility to echinocandins in C. guilliermondii and C. fermentati due to naturally occurring polymorphisms in the FKS1 hotspot regions [48], are usually registered in clinical isolates but the therapeutic level of drugs seems to be enough to successfully treat their infections [49].

In addition, the finding of the low level of azole or echinocandin resistance phenomena in the many Candida spp. herein registered is in accordance with the fact that azoles and echinocandins resistance is uncommon $(<1 \%)$ for Candida spp causing invasive fungal infections (IFIs) in patients from Southern Italy hospitals [50,51]. All these findings might suggest that wild boards have no previous history of exposure to drugs or antifungal residues in the environment [52]. However, since azole fungicides are frequently used to treat fungal infections in agriculture, the acquisition of resistant phenomena is becoming a worldwide treat in the recent [53] and could at some point affect wild animals. Thus, the resistance rate registered from yeasts, isolated from wild boar, associated to the fact that wild boar is unlikely of being treated with antifungal drugs, might also suggest the importance of these animal species as bioindicator of a good environmental quality.

In conclusion, this study showed for the first time the important role of wild boars in dissemination of pathogenic fungi in the environment, highlighting their potential role in zoonotic transmission of these microorganisms to immune-compromised human/animal hosts. The absence of resistance phenomena in the C. albicans and Candida non-albicans spp. strains from wild boar might reflect environmental free from residues of azoles antifungals pollution or chemical. Due to the ability of wild board to passively carry yeasts without affecting their susceptibility, these animals should be proposed as bio indicators of environment quality and/or as sentinel animal species for revelling the emergence of azole resistance phenomena. Further studies are needed in order to better understand the life cycle of pathogens and to disclose the evolution of resistance during transmission of yeast from wildlife animal to livestock/environment or human and vice versa. 


\section{Declarations}

Authors Contributions

Rhimi Wafa and Claudia Cafarchia conceptualised the study and wrote the manuscript. Sgroi Giovanni and Vincenzo Veneziano collected and verified animal information. Rhimi Wafa and Aneke Chioma Inyang performed the research. Giada Annoscia, Maria Stefania Latrofa and Ana Alastruey-lzquierdo have contributed on the identification of organism. Wafa Rhimi and Cafarchia Claudia and Ana Alastruey-Izquierdo analyzed and interpreted data. Cafarchia Claudia, Otranto Domenico and Ana Alastruey-Izquierdo revised, edited, and made intellectual inputs in the manuscripts. All authors read and approved the final manuscript.

Funding

This study has been partially financed by the Fondo de Investigaciones Sanitarias from the Instituto de Salud Carlos III (grant number PI20CIII/00043).

\section{Availability of Data and Materials}

Sequences were deposited in GenBank under accession numbers MW279244- MW279253.

Compliance with ethical standards

\section{Conflict of interest}

The authors declare no conflict of interest.

\section{Ethical Statement}

This study is a part of the project 'Piano Emergenza Cinghiali in Campania - PECC 2016-2019' (protocol number: Decreto Dirigenziale no. 210-Piano B7 DPAR 2018) that was approved by Institute for Environmental Protection and Research (ISPRA). The approval letter has been included in Supplementary Material.

\section{References}

1. Seyedmousavi S, De MG, Bosco S, De Hoog S, et al. Fungal infections in animals: a patchwork of different situations. Med Mycol. 2018;56:165-87. doi.org/10.1093/mmy/myx104.

2. Merseguel KB, Nishikaku AS, Rodrigues AM, et al. Genetic diversity of medically important and emerging Candida species causing invasive infection. BMC Infect Dis. 2015;15:57. doi.org/10.1186/s12879-015-0793-3.

3. McManus BA, Coleman DC. Molecular epidemiology, phylogeny, and evolution of Candida albicans. Infect Genet Evol. 2014;21:166-78. doi.org/10.1016/j.meegid.2013.11.008.

4. Schelenz S, Hagen F, Rhodes JL, et al. First hospital outbreak of the globally emerging Candida auris in a European hospital. Antimicrob Resist Infect Control. 2016;5:35. doi.org/10.1186/s13756-016-0132-5.

5. Mancianti F, Nardoni S, Ceccherelli R. Occurrence of yeasts in psittacines droppings from captive birds in Italy. Mycopathologia. 2002;153(3):121. doi:10.1023/a:1014576304894.

6. Meng XJ, Lindsay DS, Sriranganathan N. Wild boars as sources for infectious diseases in livestock and humans. Philos Trans R Soc Lond B Biol Sci. 2009;364(1530):2697-707. doi.org/10.1098/rstb.2009.0086.

7. Sgroi G, Varcasia A, Dessì G, et al. Cystic echinococcosis in wild boars (Sus scrofa) from southern Italy: epidemiological survey and molecular characterization. J Parasitol Parasites Wildl. 2019;9:305-11. doi.org/10.1016/j.ijppaw.2019.04.013.

8. Brilhante RSN, Castelo-Branco DDSCM, Soares GDP, et al. Characterization of the gastrointestinal yeast microbiota of cockatiels (Nymphicus hollandicus): a potential hazard to human health. J Med Microbiol. 2010;59(6):718-23. doi.org/10.1099/jmm.0.017426-0.

9. Rhimi W, Aneke Cl, Annoscia G, et al. Virulence and in vitro antifungal susceptibility of Candida albicans and Candida catenulata from laying hens. Int Microbiol. 2020;24(1):57-63. doi: 10.1007/s10123-020-00141-1.

10. Lord AT, Mohandas K, Somanath S, Ambu S. Multidrug resistant yeasts in synanthropic wild birds. Ann Clin Microbiol Antimicrob. 2010;9(1):11.

11. Cafarchia C, latta R, Danesi P, Camarda A, Capelli G, Otranto D. Yeasts isolated from cloacal swabs, feces, and eggs of laying hens. Med Mycol. 2019;57(3):340-345. doi: 10.1093/mmy/myy026. PMID: 29762763.

12. Stillfried M, Gras P, Busch M, Börner K, Kramer-Schadt S, Ortmann S. Wild inside: Urban wild boar select natural, not anthropogenic food resource. PLoS ONE. 2017;12(4):e0175127. doi.org/10.1371/journal.pone.0175127.

13. Pittiglio C, Khomenko S, Beltran-Alcrudo D. Wild boar mapping using population-density statistics: From polygons to high resolution raster maps. PloS one. 2018;13(5):e0193295. doi.org/10.1371/journal.pone.0193295.

14. Vittecoq M, Godreuil S, Prugnolle F. Antimicrobial resistance in wildlife. J Appl Ecol. 2016;53(2):519-29. doi/10.1111/1365-2664.12596.

15. Popova T, Todev I. Atypical mycosis in wild boars. Tradit mod vet med. 2018;1(4):21-4. Press. New York.

16. Hall TA. BioEdit:. A User-Friendly Biological Sequence Alignment Editor and Analysis Program for Windows 95/98/NT. Nucleic Acids Symp Ser. $1999 ; 41: 95-8$. 
17. Kimura MA. Simple Method for Estimating Evolutionary Rate of Base Substitutions through Comparative Studies of Nucleotide Sequences. J Mol Evol. 1980;16:111-20. doi.org/10.1007/BF01731581.

18. Tamura K, Peterson D, Peterson N, Stecher G, Nei M, Kumar S. MEGA5: molecular evolutionary genetics analysis using maximum likelihood, evolutionary distance, and maximum parsimony methods. Mol Biol Evol. 2011;28(10):2731-9.

19. Tamura K. Estimation of the number of nucleotide substitutions when there are strong transition-transversion and $\mathrm{G}+\mathrm{C}$ - content biases. Mol Biol Evol. 1992;9:678-87.

20. Nei M, Kumar S, Molecular Evolution and Phylogenetics. Oxford University 2000.

21. Tamura K, Stecher G, Peterson D, Filipski A, Kumar S. 2013. MEGA6: molecular evolutionary genetics analysis version 6.0. Mol. Biol. Evol. 2013;30(12), 2725-2729. Taylor LH, Latham SM, Woolhouse ME. Risk factors for human disease emergence. Philos Trans R Soc Lond B Biol Sci. 2001;356(1411):983-9. doi: 10.1098/rstb.2001.0888. PMID: 11516376; PMCID: PMC1088493.

22. Arendrup MC, Cuenca-Estrella M, Lass-Flörl C, Hope W. EUCAST-AFST. EUCAST technical note on the EUCAST definitive document EDef 7.2: method for the determination of broth dilution minimum inhibitory concentrations of antifungal agents for yeasts EDef 7.2 (EUCAST-AFST). Clin Microbiol Infect. 2012;18(7):E246-7. doi:10.1111/j.1469-0691.2012.03880.x.

23. Arendrup MC, Friberg N, Mares M, Kahlmeter G, Meletiadis J, Guinea J. Subcommittee on Antifungal Susceptibility Testing (AFST) of the ESCMID European Committee for Antimicrobial Susceptibility Testing (EUCAST). How to interpret MICs of antifungal compounds according to the revised clinical breakpoints v. 10.0 European committee on antimicrobial susceptibility testing (EUCAST). Clin Microbiol Infect. 2020;26(11):1464-72. doi:10.1016/j.cmi.2020.06.007. Epub 2020 Jun 17. PMID: 32562861.

24. Pfaller MA, Diekema DJ, Andes D, et al. Clinical breakpoints for the echinocandins and Candida revisited: integration of molecular, clinical, and microbiological data to arrive at species-specific interpretive criteria. Drug Resist Updat. 2011;14(3):164-76. doi.org/10.1016/j.drup.2011.01.004.

25. Thompson GR, Nathan P. Wiederhold. Isavuconazole: a comprehensive review of spectrum of activity of a new triazole. Mycopathologia. 2010;170(5):291-313. doi:10.1007/s11046-010-9324-3.

26. Lindberg E, Hammarström H, Ataollahy N, Kondori N. Species distribution and antifungal drug susceptibilities of yeasts isolated from the blood samples of patients with candidemia. Sci Rep. 2019;9(1):1-6. doi:10.1038/s41598-019-40280-8.

27. Shamim SUMBUL, Ahmed SW, Siddiqui SA, Azhar IQBAL. Superficial mycoses: a study performed for the isolation and identification of fungal species from infected patients. Pak J Pharm Sci. 2005;22(1):41-6.

28. Lemel J, Truvé J, Söderberg B. Variation in ranging and activity behaviour of European wild boar Sus scrofa in Sweden. Wildlife Biol. 2003;9(1):29-36. doi.org/10.2981/wlb.2003.061.

29. Piattoni F, Ori, Francesca, Morara M, lotti M, Zambonelli A. The role of wild boars in spore dispersal of hypogeous fungi. Acta Mycol. 2012;47 (2). doi:10.5586/am.2012.017.

30. Willis KA, Purvis JH, Myers ED, et al. Fungi form interkingdom microbial communities in the primordial human gut that develop with gestational age. FASEB J. 2019;33(11):12825-37. doi.org/10.1096/fj.201901436RR.

31. Limon JJ, Skalski JH, Underhill DM. Commensal fungi in health and disease. Cell host microbe. 2017;22(2):156-65. doi:10.1016/j.chom.2017.07.002.

32. Acevedo P, Escudero MA, Muñoz R. Gortazar C. Factors affecting wild boar abundance across an environmental gradient in Spain. Acta Theriol. 2006;51:327-36. doi.org/10.1007/BF03192685.

33. Pfaller MA, Diekema DJ. Epidemiology of invasive candidiasis: a persistent public health problem. Clin Microbiol Rev. 2007;20:133-63. doi.org/10.1128/CMR.00029-06.

34. Lass-Flörl C. The changing face of epidemiology of invasive fungal disease in Europe. Mycoses. 2009;52(3):197-205. doi:10.1111/j.14390507.2009.01691.x.

35. Cafarchia C, Camarda A, Romito D, et al. Occurrence of yeasts in cloacae of migratory birds. Mycopathologia. 2006;161:229-34. doi.org/10.1007/s11046-005-0194-z.

36. Trofa D, Gácser A, Nosanchuk JD. Candida parapsilosis, an emerging fungal pathogen. Clin Microbiol Rev. 2008;21(4):606-25. doi/10.1128/CMR.0001308.

37. Pfaller MA, Pappas PG, Wingard JR. Invasive fungal pathogens: current epidemiological trends. Clin Infect Dis. 2006;43(S1):3-14. doi:10.1086/504490.

38. Urubschurov V, Janczyk P, Pieper R, et al. Biological diversity of yeasts in the gastrointestinal tract of weaned piglets kept under different farm conditions. FEMS Yeast Res. 2008;8:1349-56.

39. Wawrysiuk S, Rechberger T, Futyma K, Miotła P. Candida lusitaniae - a case report of an intraperitoneal infection. Prz Menopauzalny. 2018;17(2):94. doi:10.5114/pm.2018.77310.

40. Romi W, Keisam S, Ahmed G, Jeyaram K. Reliable differentiation of Meyerozyma guilliermondii from Meyerozyma caribbica by internal transcribed spacer restriction fingerprinting. BMC Microbiol. 2014;14(1):52. doi:10.1186/1471-2180-14-52.

41. Zhang X, Xu Z, Pei H, et al. Intraspecific variation and phylogenetic relationships are revealed by ITS1 secondary structure analysis and single-nucleotide polymorphism in Ganoderma lucidum. PloS one. 2017;12(1):e0169042. doi.org/10.1371/journal.pone.0169042.

42. Maganti H, Bartfai D, Xu J. Ecological structuring of yeasts associated with trees around Hamilton, Ontario, Canada. FEMS Yeast Res. 2012;12(1):9-19. doi.org/10.1111/j.1567-1364.2011.00756.x.

43. Gortázar C, Ferroglio E, Höfle U, Frölich K, Vicente J. Diseases shared between wildlife and livestock: a European perspective. Eur J Wildl Res. 2007;53:241-56. doi.org/10.1007/s10344-007-0098-y. 
44. Madhavan P, Jamal F, Pei CP, Othman F, Karunanidhi A, Ng KP. Comparative study of the effects of fluconazole and voriconazole on Candida glabrata, Candida parapsilosis and Candida rugosa biofilms. Mycopathologia. 2018;183(3):499-511. doi:10.1007/s11046-018-0243-z.

45. Marcos-Zambrano LJ, Gómez A, Sßnchez-Carrillo, et al. Isavuconazole is highly active in á vitro against Candida species isolates but shows trailing effect. Clin Microbiol Infect. 2018;24(12):1343-e1. doi.org/10.1016/j.cmi.2018.07.006.

46. Ksiezopolska E, Gabaldón T. Evolutionary emergence of drug resistance in Candida opportunistic pathogens. Genes. 2018;9(9):461. doi.org/10.3390/genes9090461.

47. Summers KL, Foster Frey J, Arfken AM. Characterization of Kazachstania slooffiae, a Proposed Commensal in the Porcine Gut. J Fungi (Basel). 2021;7(2):146. doi:10.3390/jof7020146.

48. Castanheira M, Woosley LN, Diekema DJ, Messer SA, Jones RN, Pfaller MA. Low prevalence of fks1 hot spot 1 mutations in a worldwide collection of Candida strains. Antimicrob Agents Chemother. 2010;54(6):2655-9. doi:10.1128/AAC.01711-09.

49. Hirayama T, MiyazakiT, Yamagishi Y, et al. Clinical and microbiological characteristics of Candida guilliermondii and Candida fermentati. Antimicrob Agents Chemother. 2018;62(6):e02528-17. doi:10.1128/AAC.02528-17.

50. Montagna MT, Caggiano G, Lovero G, et al. Epidemiology of invasive fungal infections in the intensive care unit: results of a multicenter Italian survey (AURORA Project). Infection. 2013;41(3):645-53. doi:10.1007/s15010-013-0432-0.

51. Caggiano G, Coretti C, Bartolomeo N, Lovero G, De Giglio O, Montagna MT. Candida bloodstream infections in Italy: changing epidemiology during 16 years of surveillance. Biomed Res Int. 2015; 256580. doi:10.1155/2015/256580.

52. Castelo-Branco DDSCM, Paiva MDAN, Teixeira CEC, et al. Azole resistance in Candida from animals calls for the One Health approach to tackle the emergence of antimicrobial resistance. Med Mycol. 2020;58(7):896-905. doi:10.1093/mmy/myz135.

53. Berman J, Krysan DJ. Drug resistance and tolerance in fungi. Nat Rev Microbiol. 2020;18:319-31. https://doi.org/10.1038/s41579-019-0322-2.

\section{Figures}

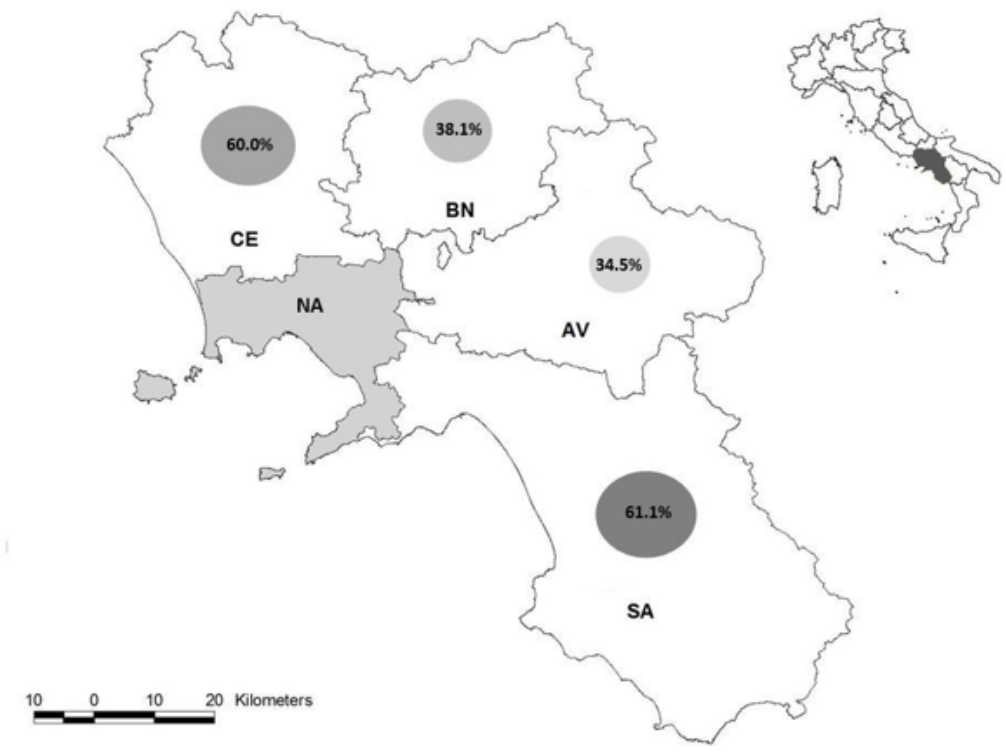

\section{Figure 1}

Map with proportioned circles showing wild boars positive to different kind of yeasts collected from each province examined (Avellino - AV; Benevento - BN; Caserta - CE; Salerno - SA) in Campania region, southern Italy. The province of Napoli (NA) was not investigated 


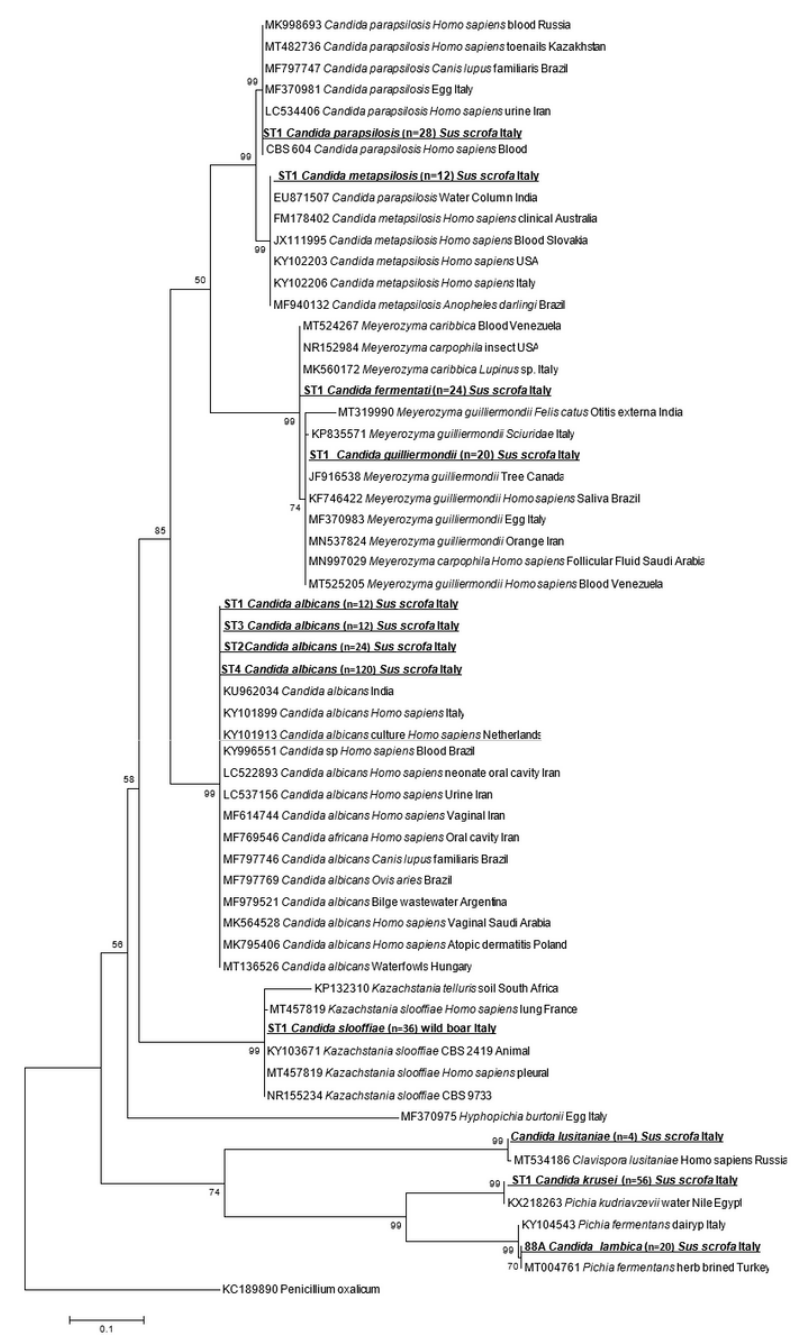

\section{Figure 2}

Phylogenetic tree based on internal transcribed spacer (ITS) sequence data with those of other yeasts available in the GenBank database. The tree was constructed using the Maximum Likelihood (ML) method on 8000 replicates and rooted against Penicillium oxalicum as outgroup. Bootstrap value $>50 \%$ are indicated 